\title{
Frequency of the toxic shock syndrome toxin-1 gene in methicillin-susceptible and -resistant Staphylococcus aureus isolates from teaching hospitals in Shiraz, Iran
}

\author{
Mohammad Motamedifar ${ }^{[1], ~[2], ~ H a d i ~ S e d i g h ~ E b r a h i m-S a r a i e ~}{ }^{[1],}$ \\ Seyedeh Mahsan Hoseini Alfatemi ${ }^{[1]}$, Mehrdad Zalipour ${ }^{[1]}, M^{1}$ hammad Kaveh ${ }^{[1]}$ \\ and Hossein Khoshkharam-Roodmajani ${ }^{[1]}$
}

[1]. Department of Bacteriology \& Virology, School of Medicine, Shiraz University of Medical Sciences, Shiraz, Iran. [2]. Shiraz HIV/AIDS Research Center, Shiraz University of Medical Sciences, Shiraz, Iran.

\begin{abstract}
Introduction: Staphylococcus aureus produces a range of virulence factors such as toxic shock syndrome toxin-1. Methods: In this cross-sectional study of 345 clinical $S$. aureus isolates, the presence of the tst gene was assessed by polymerase chain reaction (PCR). Results: The study revealed 53/345 (15.4\%) isolates were positive for the $t s t$ gene. The $t s t$ gene was present in $18.1 \%$ of methicillin-susceptible $S$. aureus (MSSA) isolates and $11.6 \%$ of methicillin-resistant $S$. aureus (MRSA) isolates $(\mathrm{p}=0.136)$. Conclusions: These results reveal the remarkable risk of $S$. aureus infections in hospitals, regardless of methicillinresistance status.
\end{abstract}

Keywords: Toxic shock syndrome toxin-1. Staphylococcus aureus. Iran.

Staphylococcus aureus is a common threat to hospitalized patients and is responsible for a variety of infections, ranging from superficial skin and soft tissue infections to toxic shock syndrome and severe systemic infections ${ }^{(1)}$. Furthermore, methicillinresistant Staphylococcus aureus (MRSA) has become a major concern in the hospital environment. Methicillin resistance in S. aureus is conferred by penicillin binding protein $2 \mathrm{a}$ ( $\mathrm{PBP} 2 \mathrm{a}$ ), encoded by the $m e c A$ gene located on a genetic element called the staphylococcal cassette chromosome (SCC) ${ }^{(2)}$. Staphylococcus aureus produce a remarkable range of secreted virulence factors that facilitate their pathogenicity, such as toxic shock syndrome toxin-1 $(\text { TSST- } 1)^{(1)}$. TSST-1 is known as a superantigen for its ability to non-specifically stimulate activation of $\mathrm{T}$ lymphocytes ${ }^{(3)}$. TSST-1 is encoded by $t s t H$, which is located on the bacterial chromosome within a 15.2-kb mobile genetic element; it has been associated with several acute or chronic human diseases, including toxic shock syndrome (TSS) ${ }^{(3)}$. TSS is an acute and potentially fatal illness characterized by high fever, diffuse erythematous rash, desquamation of the skin 1 to 2

Address to: Dr. Hadi Sedigh Ebrahim-Saraie. Dept Bacteriology \& Virology/ School of Medicine/Shiraz University of Medical Sciences. Zand St, Imam Hossein Sq, Shiraz, Iran.

Phone: 98936 882-9763; Fax: 98711 230-4356

e-mail: seddigh.hadi@gmail.com

Received 13 June 2014

Accepted 14 October 2014 weeks after the onset (if not fatal before this time), hypotension, and involvement of three or more organ systems ${ }^{(3)}$.

Characterizing the differences in the pathogenicity and virulence patterns of MRSA and methicillin-susceptible S. aureus (MSSA) could help manage hospitalization time and mortality ${ }^{(1)}$ (3). A recent study of clinical MRSA isolates from, Shiraz, Iran demonstrated the prevalence of several toxin genes, including $t s t^{(1)}$. The aim of this study was to compare the prevalence of the tst gene in clinical MSSA and MRSA isolates in Shiraz, a major city in southwest Iran.

This cross-sectional study was conducted in 2012-2013 at the Namazee and Faghihi hospitals in Shiraz. These are major tertiary care hospitals with 1,000 beds; both are affiliated with the Shiraz University of Medical Science. Samples included 345 S. aureus isolates obtained from various clinical specimens such as blood, pus, wounds, and urine. Specimens were collected from different wards in each hospital. Duplicate isolates and specimens labeled as 'outpatient' were excluded. The isolates were identified as $S$. aureus by conventional microbiologic procedures (colony morphology, Gram staining, catalase activity, growth on mannitol salt agar, DNase test, and tube coagulase). Preliminary identification of MRSA and MSSA was based on resistance to cefoxitin (30 $\mu \mathrm{g})$ (MAST company, United Kingdom) by the disc diffusion assay according to Clinical and Laboratory Standards Institute (CLSI) guidelines $^{(4)}$. Staphylococcus aureus ATCC 25923 (an MSSA) was used as the control for antibacterial susceptibility testing. Confirmed isolates were stored at $-80^{\circ} \mathrm{C}$ for long-term preservation. 
Genomic deoxyribonucleic acid (DNA) was extracted by using the small-scale phenol-chloroform extraction method ${ }^{(5)}$. DNA concentrations were determined by spectrophotometry at $\mathrm{A}_{260}$ based on $\mu \mathrm{g} / \mathrm{mL}$ concentration. In this study, DNA sample quantities ranged from 10 to $1,000 \mathrm{ng}$. DNA was preserved at $-20^{\circ} \mathrm{C}$. The phenotypically confirmed MRSA isolates were subsequently tested for the presence of $m e c A$ as described by Zhang et al. ${ }^{(6)}$. All MRSA and MSSA isolates were also assayed for the presence of the $t$ st gene by using previously described primers $^{(7)}$. MRSA reference strains JCSC/4469 were used as positive mecA and tst gene controls. Reference strains were kindly provided by Professor Alborzi Clinical Microbiology Research Center, Shiraz, Iran. Polymerase chain reaction (PCR) amplifications were performed using a DNA Thermal Cycler 5530 (Eppendorf, Germany). PCR products were mixed with $1 \mu$ l loading buffer and separated by $1.5 \%$ agarose gel electrophoresis at $75 \mathrm{~V}$ for $90 \mathrm{~min}$. The gel was stained with ethidium bromide (Merck, Germany) for $15 \mathrm{~min}$ and observed under the UV trans-illuminator. Statistical analysis was performed using SPSS software, version 19.0. Chi-square or Fisher's exact tests were performed to analyze the results. $\mathrm{P}<0.05$ was regarded as significant.

Of the 345 Staphylococcus aureus isolates included in this study, $42.3 \%$ were found to be MRSA by cefoxitin disk and mecA PCR; 57.7\% were methicillin-susceptible isolates. Namazee hospital yielded 69 (44.8\%) MRSA and 85 (55.2\%) MSSA isolates. Faghihi hospital yielded 77 (40.3\%) MRSA and $114(59.7 \%)$ MSSA isolates. There was no significant difference in the rates of MRSA and MSSA between hospitals.

PCR assays revealed $53(15.4 \%)$ isolates positive for the tst gene. A representative gel image of $t s t$ gene detection by PCR is shown in Figure 1. The distribution of tst among the $S$. aureus isolates is presented in Table 1. Despite the high frequency of $t$ st in the MSSA versus MRSA isolates, statistical analysis showed no significant differences. The prevalence of toxin genes in different clinical specimens is shown in Table 2. The main clinical sources of tst were sputum, wound, and skin specimens, each of which yielded 11 positive samples. Ear specimens showed 2 out of 2 samples were positive for the tst gene. The tst gene distribution was more variable among clinical specimens in MSSA isolates, since $t$ ts was detected in 10 different specimens. The $t s t$ gene was detected in more isolates from Faghihi hospital $(n=33)$ than from Namazee $(n=20)$, but the difference did not reach statistical significance.

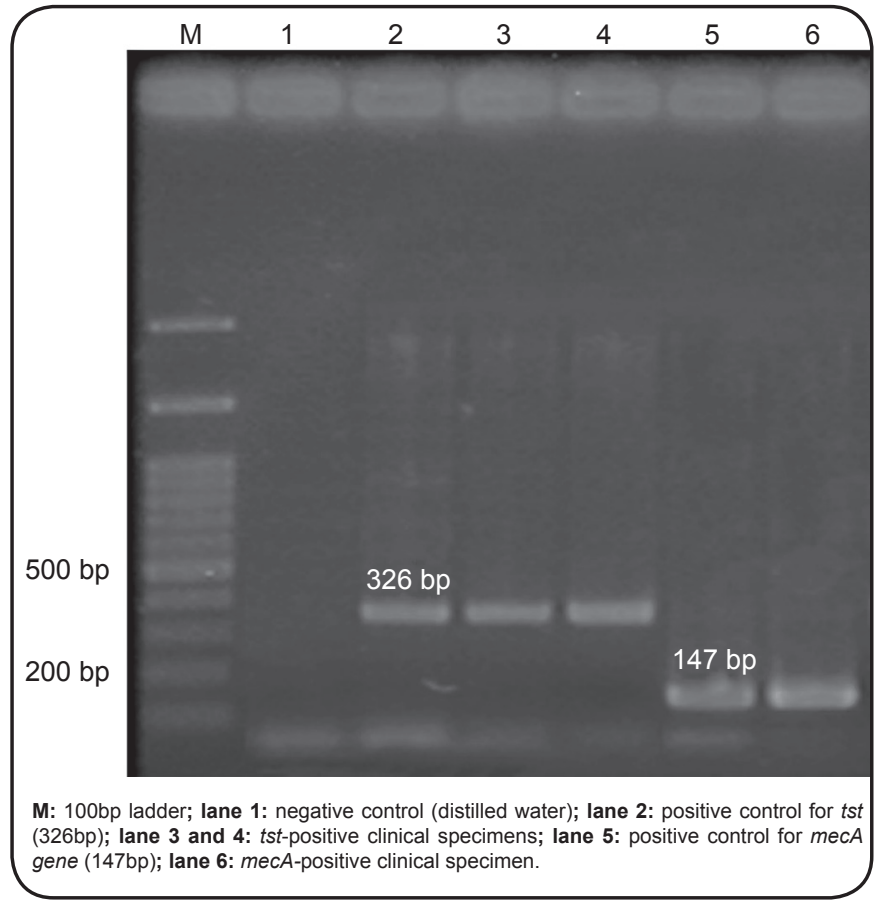

FIGURE 1 - A representative gel image of $m e c A$ and $t$ st gene detection by PCR.

In this study of southwest Iranian hospitals, we identified $53(15.4 \%)$ isolates positive for the gene encoding TSST-1. In the north (Tehran) and north-east (Tabriz) of Iran, the tst-positive rates are $12.8 \%$ and $17.4 \%$, respectively ${ }^{(8)}{ }^{(9)}$. Studies in Turkey and Colombia showed $t$ st-positive rates of $14.2 \%$ and $18 \%{ }^{(10)(11)}$.

The frequency of the $t$ st gene was numerically higher in our MSSA isolates than in the MRSA isolates (18.1\% vs. $11.6 \%$ ), although the difference was not significant. Jiménez et al. also showed a greater frequency of $t s t$ in MSSA versus MRSA isolates from pediatric patients ${ }^{(11)}$. Sila et $\mathrm{al}^{(12)}$. from the $\mathrm{Czech}$ Republic reported the $6 \%$ of $t$ st-carrying MSSA were more virulent than $2 \%$ of tst-carrying $\operatorname{MRSA}^{(12)}$.

Although we identified no significant overall difference in the prevalence of tst gene between MRSA and MSSA isolates. We did observe a significant difference in isolates from blood, with $20 \%$ of MRSA versus $7.7 \%$ of MSSA isolates carrying the

TABLE 1 - The distribution of tst in clinical isolates of Staphylococcus aureus from two hospitals.

\begin{tabular}{|c|c|c|c|c|c|c|c|}
\hline $\begin{array}{l}\text { Isolates } \\
\text { Hospitals }\end{array}$ & \multicolumn{2}{|c|}{ MRSA } & $\begin{array}{c}\text { level of } \\
\text { significance }^{a}\end{array}$ & \multicolumn{2}{|c|}{ MSSA } & $\begin{array}{c}\text { Level of } \\
\text { significance }^{b}\end{array}$ & $\begin{array}{c}\text { Level of } \\
\text { significance }\end{array}$ \\
\hline Faghihi & 11 & 14.3 & $\mathrm{p}=0.428$ & 22 & 19.3 & $\mathrm{p}=0.744$ & $\mathrm{p}=0.481$ \\
\hline Namazee & 6 & 8.7 & & 14 & 16.5 & & $\mathrm{p}=0.235$ \\
\hline Total & 17 & 11.6 & & 36 & 18.1 & $\mathrm{p}=0.136^{\mathrm{d}}$ & \\
\hline
\end{tabular}

MRSA: methicillin-resistant Staphylococcus aureus; MSSA: methicillin-susceptible Staphylococcus aureus; a estimated p value for MRSA;




TABLE 2 - The prevalence of tst in Staphylococcus aureus isolates according to clinical specimen.

\begin{tabular}{|c|c|c|c|c|c|}
\hline & \multicolumn{2}{|c|}{ Faghihi Hospital } & \multicolumn{2}{|c|}{ Namazee Hospital } & \multirow[b]{2}{*}{ Total } \\
\hline & MRSA & MSSA & MRSA & MSSA & \\
\hline & $\begin{array}{c}\text { number } \\
\text { positive/total }\end{array}$ & $\begin{array}{c}\text { number } \\
\text { positive/total }\end{array}$ & $\begin{array}{c}\text { number } \\
\text { positive/total }\end{array}$ & $\begin{array}{c}\text { number } \\
\text { positive/total }\end{array}$ & $\begin{array}{c}\text { number } \\
\text { positive/total }\end{array}$ \\
\hline Sputum & $3 / 35$ & $4 / 16$ & $0 / 23$ & $4 / 19$ & $11 / 93$ \\
\hline Urine & $0 / 9$ & $4 / 26$ & $0 / 5$ & $1 / 11$ & $5 / 51$ \\
\hline Wound & $2 / 8$ & $1 / 13$ & $3 / 10$ & $5 / 10$ & $11 / 41$ \\
\hline Nose & $0 / 2$ & $1 / 16$ & $1 / 1$ & $2 / 8$ & $4 / 27$ \\
\hline Skin & $4 / 8$ & $7 / 17$ & NS & NS & $11 / 25$ \\
\hline Throat & $0 / 1$ & $1 / 4$ & $0 / 3$ & $0 / 4$ & $1 / 12$ \\
\hline Total & $11 / 77$ & $22 / 114$ & $6 / 69$ & $14 / 85$ & $53 / 345$ \\
\hline
\end{tabular}

MRSA: methicillin-resistant Staphylococcus aureus; MSSA: methicillin-susceptible Staphylococcus aureus; NS: no sample; CSF: cerebrospinal fluid.

tst gene. Peck et al ${ }^{(13)}$. reported that TSST-1 producing MRSA isolates were more prevalent in blood samples ${ }^{(13)}$.

Although we identified sputum, wounds, and skin as three major sources of TSST-1 producing isolates, wounds are the most common source for isolation of TSST-1 producing $S$. aureus. Teyhoo et al. from Iran and Daghistani et al. from Jordan reported substantial rates of tst-harboring $S$. aureus isolates from wound samples ${ }^{(9)(14)}$.

In this study, the skin was most frequently associated with tst-carrying isolates, with twice the rate of detection (44\%) in comparison to sputum and wounds. This high rate of TSST-1 producing $S$. aureus isolates may be considered a risk factor for vulnerable groups such as newborns and patients with atopic dermatitis ${ }^{(15)}$. As virulence factors accelerate colonization and invasion through minor breaks in the skin and mucus membranes, the subsequent spread of TSST-1 producing $S$. aureus to the bloodstream could have a critical influence on clinical outcomes ${ }^{(14)}$.

MRSA isolates are known to be more antibiotic resistant than MSSA isolates and antimicrobial resistance may generally be considered an important factor for the clinical outcome of $S$. aureus infection as well ${ }^{(11)}$. However, a higher rate of TSST-1 carrying isolates was detected among MSSA isolates compared to that for MRSA isolates, although the difference was not statistically significant in our study. So, MSSA isolates might be more virulent in term of TSST-1 than MRSA isolates. We suggest the most dangerous $S$. aureus are not necessarily those with the most antibiotic resistance. Antibiotic resistance is thought to impose a fitness cost associated with a reduction in toxin production ${ }^{(3)(11)}$, it is not surprising that our MRSA isolates showed less toxin rate.
In summary, we have shown a frequency of up to $15 \%$ tst-positivity in MSSA and MRSA isolates and suggesting methicillin resistance has no effect on acquisition of the virulence gene. We conclude that the risk of infection with S. aureus should not be assigned only based on methicillin resistance.

\section{ACKNOWLEDGMENTS}

The authors would like to thank Ms. N. Pirbonyeh and Dr. Jamal Sarvari for technical assistance.

\section{CONFLICT OF INTEREST}

The authors declare that there is no conflict of interest.

\section{FINANCIAL SUPPORT}

This study was supported by Shiraz University of Medical Sciences grant number 92-6513.

\section{REFERENCES}

1. Hoseini Alfatemi SM, Motamedifar M, Hadi N, Sedigh Ebrahim Saraie H. Analysis of Virulence Genes Among Methicillin Resistant Staphylococcus aureus (MRSA) Strains. Jundishapur J Microbiol 2014; 7:e10741.

2. Turlej A, Hryniewicz W, Empel J. Staphylococcal cassette chromosome mec (SCCmec) classification and typing methods: an overview. Pol J Microbiol 2011; 60:95-103. 
3. Dinges MM, Orwin PM, Schlievert PM. Exotoxins of Staphylococcus aureus. Clin Microbiol Rev 2000; 13:16-34.

4. Clinical and Laboratory Standards Institute (CLSI). Performance Standards for Antimicrobial Susceptibility Testing. 21 ${ }^{\text {th }}$ Informational Supplement. M100-S21. Wayne, PA: CLSI; 2011.

5. Sambrook J, Russell DW. Purification of nucleic acids by extraction with phenol:chloroform. CSH Protoc 2006; 1(1). doi:10.1101/pdb. prot4455.

6. Zhang K, McClure JA, Elsayed S, Louie T, Conly JM. Novel multiplex PCR assay for characterization and concomitant subtyping of staphylococcal cassette chromosome mec types I to $\mathrm{V}$ in methicillin-resistant Staphylococcus aureus. J Clin Microbiol 2005; 43:5026-5033.

7. Mehrotra M, Wang G, Johnson WM. Multiplex PCR for detection of genes for Staphylococcus aureus enterotoxins, exfoliative toxins, toxic shock syndrome toxin 1 , and methicillin resistance. J Clin Microbiol 2000; 38:1032-1035.

8. Sabouni F, Mahmoudi S, Bahador A, Pourakbari B, Sadeghi RH, Ashtiani MTH, et al. Virulence Factors of Staphylococcus aureus Isolates in an Iranian Referral Children's Hospital. Osong Public Health Res Perspect 2014; 5:96-100.

9. Teyhoo M, Mobaiyen H, Amirmozafari N, Moaddab SR, Mones rast S. Prevalence of toxic shock syndrome toxin I producing clinical isolates of Staphylococcus aureus strains isolated from hospitals in Tabriz, Iran. Int J Biosci 2014; 4:169-176.
10. Demir C, Aslantas O, Duran N, Ocak S, Ozer B. Investigation of toxin genes in Staphylococcus aureus strains isolates in Mustafa Kemal University Hospital. Turk J Med Sci 2011; 41:343-352.

11. Jimenez JN, Ocampo AM, Vanegas JM, Rodriguez EA, Garces CG, Patino LA, et al. Characterisation of virulence genes in methicillin susceptible and resistant Staphylococcus aureus isolates from a paediatric population in a university hospital of Medellin, Colombia. Mem Inst Oswaldo Cruz 2011; 106:980-985.

12. Sila J, Sauer P, Kolar M. Comparison of the prevalence of genes coding for enterotoxins, exfoliatins, panton-valentine leukocidin and tsst-1 between methicillin-resistant and methicillin-susceptible isolates of Staphylococcus aureus at the university hospital in olomouc. Biomed Pap Med Fac Univ Palacky Olomouc Czech Repub 2009; 153:215-218.

13. Peck KR, Baek JY, Song JH, Ko KS. Comparison of genotypes and enterotoxin genes between Staphylococcus aureus isolates from blood and nasal colonizers in a Korean hospital. J Korean Med Sci 2009; 24:585-591.

14. Daghistani HI, Issa AA, Shehabi AA. Frequency of nasal and wound isolates of Staphylococcus aureus associated with TSST-1 production in Jordanian population. FEMS Immunol Med Microbiol 2000; 27:95-98.

15. Schlievert PM, Strandberg KL, Lin YC, Peterson ML, Leung DY. Secreted virulence factor comparison between methicillin-resistant and methicillin-sensitive Staphylococcus aureus, and its relevance to atopic dermatitis. J Allergy Clin Immunol 2010; 125:39-49. 